\title{
The Pathophysiology of Malabsorption
}

\author{
Jutta Keller Peter Layer \\ Department of Internal Medicine, Israelitic Hospital, University of Hamburg, Germany
}

\section{Keywords}

Maldigestion - Malabsorption - Motility disturbances . Gastric acid secretion - Pancreatic exocrine insufficiency

\section{Summary}

Physiological digestion and absorption of nutrients within the gastrointestinal tract requires a complex interaction between motor, secretory, digestive, and absorptive functions that is vulnerable to a multitude of potential disturbances which may lead to global or specific malabsorption syndromes. Potential pathomechanisms that are illustrated in this article include insufficient mechanical breakdown of harder food components due to chewing problems and/or decreased antral contractility, critical reduction of time for absorption in patients with markedly enhanced upper gastrointestinal transit (e.g. dumping syndrome), impaired digestion and absorption of nutrient components caused by reduced gastric acid secretion, pancreatic exocrine insufficiency or reduced biliary secretion, defects of the enteral mucosa with enzyme deficiencies (e.g. disaccharidases) or lack of specific carrier mechanisms (e.g. hexose or aminoacid transporters), and critical quantitative loss of intestinal mucosa in patients with short bowel syndrome.

\section{Introduction}

Physiological digestion and absorption of nutrients within the gastrointestinal tract requires extensive interaction between secretory, motor, and absorptive functions. The complexity of this process explains why there are numerous disturbances and diseases that may cause malabsorption. While it is generally known that severe pancreatic insufficiency leads to detrimental malabsorption, it is less clear that coordinated gastrointestinal motility is also one of the basic requirements

\section{Schlüsselwörter \\ Maldigestion · Malabsorption · Motilitätsstörungen · \\ Achlorhydrie · Exokrine Pankreasinsuffizienz}

\section{Zusammenfassung}

Die physiologische Digestion und Absorption von Nährstoffen im Magen-Darm-Trakt erfordert ein komplexes Zusammenspiel motorischer, sekretorischer, digestiver und absorptiver Funktionen, das anfällig ist für eine Vielzahl möglicher Störungen, die zu globalen oder spezifischen Malabsorptionssyndromen führen können. Die in diesem Artikel beleuchteten potenziellen Pathomechanismen schließen die folgenden Störungen ein: unzureichende mechanische Zerkleinerung harter Nahrungsbestandteile bei Kauproblemen oder antraler Hypokontraktilität, kritische Verkürzung der zur Resorption zur Verfügung stehenden Zeit bei starker Beschleunigung des Transits im oberen Gastrointestinaltrakt (z.B. DumpingSyndrom), Maldigestion und Malabsorption bei unzureichender gastraler Säuresekretion, exokriner Pankreasinsuffizienz oder gestörter Gallesekretion, Enzymmangel der Enterozyten (z.B. Disaccharidasemangel) oder defekte Transportermechanismen (z.B. Hexose- oder Aminosäuretransporter) sowie kritischer quantitativer Verlust von intestinaler Mukosa bei Kurzdarmsyndrom.

for undisturbed and efficient digestion and absorption of a meal. Accordingly, milder motility disturbances can induce or contribute to symptoms such as diarrhea, constipation, and abdominal pain, while severe motility disturbances may also impair nutrient absorption. This article will give an overview over physiological processes that enable efficient digestion and absorption in healthy individuals and describe important mechanisms that lead to malabsorption throughout the gastrointestinal tract.

\section{KARGER \\ Fax +497614520714 \\ Information@Karger.com}

www.karger.com (c) 2014 S. Karger GmbH, Freibur 1662-6664/14/0303-0150\$39.50/0

Accessible online at: www.karger.com/vim
PD Dr. med. Jutta Keller

Department of Internal Medicine

Israelitic Hospital, University of Hamburg

Orchideenstieg 14, 22297 Hamburg, Germany

keller@ik-h.de 


\section{Chewing Problems and Hyposalivation}

Ingested nutrients are fragmented in the oral cavity by mastication and are mixed with saliva to form a food bolus that can easily be swallowed. People with chewing problems, especially edentulous subjects without dentures, have weight loss and an increased mortality which is probably mainly due to reduced nutrient intake. However, the masticatory process also appears to be crucial for optimal absorption of nutrients from some essential, harder food components such as meat and vegetables [1].

In addition to mechanical breakdown of food components, enzymatic digestion of nutrients by salivary enzymes also starts in the oral cavity. However, while patients with hyposalivation frequently change their diet which may result in malnutrition and weight loss, there is no evidence that hyposalivation may cause maldigestion and malabsorption. Output of salivary $\alpha$-amylase, which is the most important salivary enzyme, comprises only about $15 \%$ of total amylase output, while the rest is attributable to pancreatic $\alpha$-amylase. There is conflicting data whether in humans relevant amounts of lipolytic activity are secreted into saliva at all.

\section{Esophageal Motility Disorders}

The esophagus has no direct digestive function but serves to transport ingested material to the stomach. Weight loss is a typical sign in patients with severe esophageal motility disorders such as achalasia. Yet again, this is not caused by impaired nutrient digestion and/or absorption but is due to reduced intake in patients with dysphagia.

\section{Disturbed Gastric Motility and Secretion}

The stomach has important motor, secretory, and digestive functions while gastric absorption of food components only plays a marginal role. Since gastric motility serves to grind solids and to transport gastric contents toward the duodenum, severe gastric motility disturbances may theoretically be associated with decreased digestibility of large food particles leading to impaired absorption. However, this has not been investigated specifically. Gastric motility also mixes the food with gastric secretions and, thus, improves digestion. Markedly accelerated gastric emptying can induce dumping syndrome with malabsorption of fluids and nutrients leading to diarrhea.

Gastric secretions facilitate the digestion of proteins which commences in the stomach by acid denaturation and hydrolysis by gastric proteases or pepsins. Accordingly, proton pump inhibitor (PPI) therapy has been shown to diminish protein absorption [2]; however, this appears to be clinically irrelevant [3]. Gastric secretions also improve absorption of several micronutrients including iron, calcium, and magnesium. Absorption of minerals in the small intestine usually requires soluble molecules. Gastric acid can release minerals, almost exclusively cations, from organic food matrices and increases solubility of positively charged ions including calcium. Still, the impairment of calcium absorption in the absence of gastric acid secretion appears to be of limited clinical importance. Large studies have shown no or only a weak association between PPI therapy and development of osteoporosis [4, 5]. Impaired conditions for iron absorption can rarely lead to or deteriorate anemia in patients with atrophic gastritis, gastric resections, and vagotomy [6]. Case reports and small case series also suggest a potential association between PPI therapy and hypomagnesemia [6].

Vitamin $B_{12}$ ingested with meals is bound to food proteins. The vitamin needs to be released from these proteins and then bound to $\mathrm{R}$ proteins and intrinsic factor in order to be absorbed in the terminal ileum. Gastric acid and pepsin facilitate the proteolytic process involved in releasing the vitamin from the proteins in ingested food. Thus, not only atrophic gastritis with loss of the intrinsic factor may impair vitamin $B_{12}$ absorption but also loss of acid secretion plays a role. Shortterm PPI treatment of healthy subjects was associated with a reduction of vitamin $B_{12}$ absorption of more than $70 \%$. Longterm studies in patients have shown that vitamin $\mathrm{B}_{12}$ concentrations remain within the normal limit within the first 3 years of treatment, whereas a longer duration of therapy was associated with a small but significant downward trend.

Pepsins are not the only enzymes that are produced by the gastric mucosa in humans. In addition, gastric lipase is secreted by the chief cells of the fundus. It has been estimated that $10-20 \%$ of meal triglycerides may be hydrolyzed by gastric lipase; however, in healthy adults, the physiological role of gastric lipase is probably regulatory [7] and does not quantitatively contribute to overall lipid digestion. Accordingly, the lack of gastric lipase plays no known pathophysiological role.

\section{Maldigestion and Malabsorption of Nutrients in the Small Intestine}

\section{Disturbed Intestinal Transit and Small Intestinal Bacterial Overgrowth}

The proximal small intestine absorbs nutrients extremely efficiently: Following perfusion of nutrients into the proximal duodenum at physiological postprandial rates, up to $80 \%$ of triglycerides, $60 \%$ of carbohydrates, and $50 \%$ of proteins have been shown to be absorbed before reaching the distal duodenum $20 \mathrm{~cm}$ apart [8, 9]. However, even in healthy humans small amounts of nutrients are not absorbed during small intestinal transit but reach the terminal ileum and are delivered to the colon. Thus, most complex carbohydrates result in malabsorption rates of about $10 \%$, and lipid malab- 
sorption may amount to $5 \%$ of the dose administered [1] Physiologically malabsorbed nutrients are an important energy source for colonic bacteria and exert regulatory, mainly inhibitory effects on upper gastrointestinal functions. This socalled ileal brake mechanism likely contributes to restitution of the interdigestive secretory and motor pattern at the end of the digestive period $[10,11]$. Marked acceleration of intestinal transit can increase nutrient malabsorption and induce symptoms due to high osmotic load, increased bacterial metabolism in the colon, and disturbed regulatory mechanisms. In contrast, delayed small intestinal transit by itself does not impair the absorptive capacity of the small bowel. However, delayed transit may promote small intestinal bacterial overgrowth by facilitating colonization of the small bowel with ascending colonic bacteria. These bacteria consume part of the ingested macro- and micronutrients and may therefore cause malnutrition. In addition, deconjugation of bile acids by bacterial enzymes compromises bile acid absorption in the terminal ileum, may deplete the bile acid pool, and may therefore disturb lipid absorption.

\section{Pancreatic Exocrine Insufficiency}

Sufficient absorption of macronutrients to maintain energy supply depends on prior hydrolysis by pancreatic enzymes. In healthy individuals, the cumulative postprandial pancreatic enzyme response exceeds 10 - to 15 -fold the quantity required to prevent overt maldigestion and malabsorption. The most important inorganic component of pancreatic juice is bicarbonate which increases duodenal $\mathrm{pH}$ and, thus, enhances intraluminal enzyme activities because all pancreatic enzymes have their $\mathrm{pH}$ optima in the alkaline range [12].

$\alpha$-amylase and lipase are secreted into the duodenum in active form while proteases enter the duodenum as inactive zymogens. Trypsinogen is then partly converted to trypsin by the duodenal enzyme enteropeptidase (i.e. enterokinase), and subsequently trypsin exerts an autocatalytic effect and also activates the other proteases. Congenital enteropeptidase deficiency is an extremely rare, recessive disorder $(<20$ cases reported so far) that results in failure to thrive, diarrhea, anemia, hypoproteinemia, and edema. The condition is usually successfully treated by pancreatic enzyme replacement or by dietary administration of protein hydrolysate [13]. Interestingly, it has been recently suggested to target the enteropeptidase gene as a potential therapeutic option in obesity [13].

Isolated deficiencies of pancreatic enzymes may also occur but are extremely rare. The most important causes of pancreatic exocrine insufficiency are chronic pancreatitis in adults and cystic fibrosis in children [12]. Typically, secretion of all components of pancreatic juice is affected, though the degree of reduction may vary for individual enzymes [12]. Other pancreatic causes include acute necrotizing pancreatitis, pancreatic cancer, and surgery that also lead to loss of functioning pancreatic tissue. However, extrapancreatic disorders such as celiac disease, inflammatory bowel disease, gastric resections, and diabetes mellitus can also be associated with pancreatic exocrine insufficiency, mostly due to regulatory disturbances. For instance, in patients with untreated celiac disease, malabsorption may not only be due to destruction of the small intestinal mucosa but also due to maldigestion of macronutrients caused by impaired pancreatic enzyme release in response to a meal. Pancreatic exocrine insufficiency in these patients is mainly explained by reduced cholecystokinin (CCK) release from the diseased mucosa resulting in insufficient prandial stimulation of the pancreas [12].

In most cases, clinical symptoms (steatorrhea, signs of decreased availability of lipid-soluble vitamins) only occur when the pancreatic secretory capacity is reduced to less than $5-10 \%$ of its normal function [14]. However, the negative impact of milder disturbances on bone metabolism may have been underestimated [15]. Moreover, moderately impaired pancreatic exocrine insufficiency may contribute to dyspeptic symptoms and diarrhea, particularly in patients with additional affections of the gastrointestinal tract.

\section{Impaired Bile Acid Synthesis and Secretion}

Bile acids support the emulsification of triglycerides and form micelles with fatty acids and monoglycerides to enable absorption from the intestinal lumen (compare below). Thus, decreased luminal availability may result in or contribute to steatorrhea. While there are rare inborn errors of bile acid synthesis and transport, interruption of the enterohepatic circulation mostly due to distal ileal disease or resection is the clinically most important pathomechanism which leads to decreased luminal availability of bile acids and lipid malabsorption.

\section{Global Malabsorption Syndromes}

Loss of functioning small intestinal mucosa can impair absorption of all macro- and micronutrients. This typically affects patients with untreated celiac disease (see also article by Stein and Schuppan [16] in this issue) or other severe alterations of the small intestinal mucosa and is most obvious in patients with short bowel syndrome (SBS). As discussed in detail in the articles by Thompson [17] and Rege [18], SBS may occur after resection of more than $50 \%$ and is obligatory after resection of more than $70 \%$ of the small intestine or if less than $100 \mathrm{~cm}$ of small bowel are left [19]. It is particularly severe after resection of the ileocecal region or if the colon has been removed additionally.

In patients with $60-100 \mathrm{~cm}$ of small bowel left and preserved colon, about $70 \%$ of applied energy is reabsorbed, but absorption of individual food components may vary. While proteins are absorbed to an extent of 60-70\%, malabsorption of fat and carbohydrates may reach $50 \%$ of ingested nutrients. Carbohydrate malabsorption is of limited importance in patients with preserved colon because up to $80 \%$ of carbohydrates not absorbed by the small bowel can be absorbed after bacterial metabolism to short-chain fatty acids and thus con- 
tribute to energy supply [19]. In contrast, fat malabsorption not only leads to steatorrhea and malnutrition but is also associated with deficiencies of the fat-soluble vitamins A, D, E, and $\mathrm{K}$.

Vitamin $\mathrm{B}_{1}, \mathrm{~B}_{2}, \mathrm{~B}_{6}$, and $\mathrm{C}$ are absorbed by the entire small bowel; therefore, deficiencies of these vitamins are relatively rare. Lack of trace elements, in particular zinc and selenium, occurs in patients with SBS and results in epithelial and mesenchymal dysfunction as well as immunodeficiency.

Calcium, magnesium, and iron as well as folic acid are predominantly absorbed by the duodenum, and deficiencies are a typical consequence of expanded proximal small bowel resections. Malabsorption of calcium may be particularly severe because absorption is further hampered by the binding of calcium to malabsorbed fatty acids and by vitamin D deficiency. In contrast, the specific uptake mechanisms allowing absorption of vitamin $\mathrm{B}_{12}$ and of bile acids are limited to the terminal ileum so that deficiencies are to be expected in patients with distal small bowel resections.

\section{Malabsorption of Specific Macronutrients}

\section{Lipids}

Long-chain triglycerides are by far the most important dietary lipids. Their absorption requires previous intraluminal digestion and depends on an intricate interplay among pancreatic lipase, colipase, and bile acids. Digestive products of lipase, long-chain free fatty acids, and 2-monoacylglycerol are absorbed after incorporation into micelles. Within the enterocytes, the products of intraluminal triglyceride digestion are resynthesized to form triglycerides before they are transported to the liver. Other dietary lipids are digested by other pancreatic lipases (e.g. digestion of phospholipids by phospholipase A2, hydrolyzation of cholesteryl ester by cholesterol esterase) or can be absorbed without prior enzymatic breakdown (e.g. free cholesterol) [1]. Accordingly, pancreatic exocrine insufficiency and impaired bile acid secretion can cause lipid malabsorption, as discussed above. In addition, extensive loss of functioning intestinal mucosa such as in patients with SBS can lead to lipid malabsorption.

\section{Proteins}

Digestion of dietary and endogenous proteins by pepsins and pancreatic proteases produces small polypeptides and free amino acids; these are further hydrolyzed by brush border peptidases. Absorption mainly takes place in the proximal jejunum but other parts of the small intestine also have significant transport capacity. The transport into the enterocytes occurs by major active carrier transporters for neutral, dibasic, and dicarboxylic amino acids [1].

However, intact polypeptides can also be transported across the enterocyte membrane. Thus, in individuals with amino acid transport defects (e.g. Hartnup disorder, cystinu- ria), peptide absorption can be normal. The nutritional importance of oligopeptide absorption may be considerable because the total absorption of amino nitrogen is greater from such peptides which are more rapidly absorbed than of amino acids even in diseased intestine.

As discussed above, gastric acid suppression therapy hampers protein assimilation. However, the relative importance of gastric protein digestion is generally thought to be limited because of the high proteolytic activity delivered by the pancreas. Conversely, decreased pancreatic protease secretion may partly be compensated by gastric and small intestinal compensatory mechanisms so that protein malabsorption usually occurs later and is clinically less important than lipid malabsorption in patients with chronic pancreatitis.

\section{Carbohydrates}

Dietary carbohydrates are also predominantly absorbed within the proximal small intestine. Before small intestinal absorption can occur, complex carbohydrates need to be hydrolyzed by salivary and pancreatic amylases to glucose, maltose, maltotriose, and oligosaccharides. Together with dietary disaccharides (mainly sucrose and lactose), these metabolites are further hydrolyzed by the brush border enzymes maltase, sucrase-isomaltase, and lactase resulting in monosaccharide production. Luminal monosaccharides such as glucose and galactose are transported by carrier-mediated mechanisms across the enterocyte brush border. Up to $50 \%$ of this transport is an active process and depends on a sodium ion gradient. The main sodium-glucose cotransporter present in the human intestine is SGLT-1 [1].

Apart from this, five functional mammalian facilitated hexose carriers (GLUTs) have been characterized by molecular cloning. Of these, three are high-affinity transporters (GLUT1, GLUT-3, and GLUT-4) and one is a low-affinity transporter (GLUT-2) for glucose. GLUT-5 is primarily a fructose carrier. The expression of these transporters is regulated by glucose and several hormones. The transporters most relevant to monosaccharide absorption in the intestine are GLUT-2 and GLUT-5, which support facilitated rather than active transport [1].

Malabsorption of complex carbohydrates may thus occur due to pancreatic exocrine insufficiency but is less likely to play a major clinical role because of compensatory mechanisms, in particular salivary amylase and brush border enzymes. Indeed, it has been shown that even under virtually complete experimental inhibition of amylase activity only about $20 \%$ of a carbohydrate meal reach the terminal ileum [20]. A significant proportion of calories from carbohydrates entering the colon can still be absorbed and contributes markedly to energy supply after bacterial metabolism to shortchain fatty acids.

Defects of brush border enzymes associated with maldigestion and malabsorption of disaccharides and (relative) GLUT deficiencies can lead to malabsorption of monosaccharides. 
Clinically by far the most important carbohydrate malabsorption syndromes are caused by lactase deficiency leading to lactose intolerance as well as relative deficiency of GLUT-5 leading to intestinal fructose malabsorption. While prevalence of fructose malabsorption is not well known and appears to depend largely on dietary habits, lactase deficiency has been shown to be normal in non-Caucasian adults. In these and in Caucasians who are homozygous for the autosomal recessive wild-type gene, a progressive decline of lactase activity is observed, frequently starting in older children or youths. Since intact lactose cannot be absorbed from the small bowel, lac- tose may bind water osmotically and will be metabolized by colonic bacteria, leading to production of gas in the large bowel if ingested by a lactase-deficient subject. Typical symptoms such as diarrhea, bloating, and abdominal pain may arise from increased water load and gas content as well as from motor responses to increased distension.

\section{Disclosure Statement}

Nothing to declare.

\section{References}

1 Keller J: Gastrointestinal digestion and absorption; in Lennarz WJ, Lane MD (eds): Encyclopedia of Biological Chemistry, ed 2. Waltham, MA, Academic Press, 2013, pp 354-359.

2 Evenepoel P, Claus D, Geypens B, et al: Evidence for impaired assimilation and increased colonic fermentation of protein, related to gastric acid suppression therapy. Aliment Pharmacol Ther 1998;12:1011-1019.

3 Keller J: Brauchen wir Magensäure? Deutsch Med Wochenschr 2012;137:4.

4 Targownik LE, Lix LM, Leung S, Leslie WD: Proton-pump inhibitor use is not associated with osteoporosis or accelerated bone mineral density loss. Gastroenterology 2010;138:896-904.

$\checkmark 5$ Gray SL, LaCroix AZ, Larson J, et al: Proton pump inhibitor use, hip fracture, and change in bone mineral density in postmenopausal women: results from the Women's Health Initiative. Arch Intern Med 2010;170:765-771.

6 Ito T, Jensen RT: Association of long-term proton pump inhibitor therapy with bone fractures and effects on absorption of calcium, vitamin B12, iron, and magnesium. Curr Gastroenterol Rep 2010;12:448-457.

7 Layer P, Keller J: Gastric lipase and pancreatic exocrine insufficiency. Clin Gastroenterol Hepato 2005;3:25-27.
8 Holtmann G, Kelly DG, Sternby B, DiMagno EP: Survival of human pancreatic enzymes during small bowel transit: effect of nutrients, bile acids, and enzymes. Am J Physiol 1997;273:G553-G558.

-9 Keller J, Runzi M, Goebell H, Layer P: Duodenal and ileal nutrient deliveries regulate human intestinal motor and pancreatic responses to a meal. Am J Physiol 1997;272:G632-G637.

10 Layer P, Peschel S, Schlesinger T, Goebell H: Human pancreatic secretion and intestinal motility: effects of ileal nutrient perfusion. Am J Physiol 1990;258:G196-G201.

11 Keller J, Holst JJ, Layer P: Inhibition of human pancreatic and biliary output but not intestinal motility by physiological intraileal lipid loads. Am J Physiol Gastrointest Liver Physiol 2006;290:G704G709.

12 Keller J, Layer P: Human pancreatic exocrine response to nutrients in health and disease. Gut 2005;54(suppl 6):vi1-28

13 Braud S, Ciufolini MA, Harosh I: Enteropeptidase: a gene associated with a starvation human phenotype and a novel target for obesity treatment. PloS One 2012;7:e49612.

14 DiMagno EP, Go VL, Summerskill WH: Relations between pancreatic enzyme ouputs and malabsorption in severe pancreatic insufficiency. N Engl J Med 1973;288:813-815.
5 Dominguez-Munoz JE, Iglesias-Garcia J, VilarinoInsua M, Iglesias-Rey M: 13C-mixed triglyceride breath test to assess oral enzyme substitution therapy in patients with chronic pancreatitis. Clin Gastroenterol Hepatol 2007;5:484-488.

16 Stein J, Schuppan D: Coeliac disease - new pathophysiological findings und their implication for therapy. Viszeralmedizin 2014;26:156-165.

17 Thompson JS: Short bowel syndrome and malabsorption - causes and prevention. Viszeralmedizin 2014;26:174-178.

18 Rege A: The surgical approach to short bowel syndrome - autologous reconstruction versus transplantation. Viszeralmedizin 2014;26:179-189.

19 Keller J, Panter H, Layer P: Management of the short bowel syndrome after extensive small bowel resection. Best Pract Res Clin Gastroenterol 2004;18:977-992.

20 Layer P, Zinsmeister AR, DiMagno EP: Effects of decreasing intraluminal amylase activity on starch digestion and postprandial gastrointestinal function in humans. Gastroenterology 1986;91:41-48. 